Sri Lanka Journal of Bio-Medical Informatics 2010;1(1):86

DOI: 10.4038/sljbmi.v1i1.1499

\title{
Master of Science in Biomedical Informatics M.Sc (BMI)
}

M.Sc in Biomedical Informatics programme is a Master of Science Programme conducted by the Postgraduate Institute of Medicine (PGIM), University of Colombo in collaboration with the Department of Informatics, University of Oslo, Norway.

The project is funded by the NOMA programme for Masters Studies, managed by the Norwegian Centre for International Cooperation in Higher Education and financed by the Norwegian Agency for Development Cooperation (Norad).

The Master of Science program in Biomedical Informatics is aimed at preparing the student in the applications of computer and information technology to support and manage health care activities including those pertaining to the care of the sick, health promotion, disease prevention, bioinformatics, medical education, health sciences research and management efforts directed toward solution of problems in the delivery of health care including resource optimization and cost effectiveness.

Currently there are 30 students in this programme and they would be entering the second year of the course in the year 2010. The degree is designed to serve as the stepping stone for the students in a career in biomedical informatics and is envisaged to be the forerunner to a Doctorate in Biomedical Informatics in the future.

For more details please visit the dedicated web site <http://www.msc-bmi-pgim.org/> 